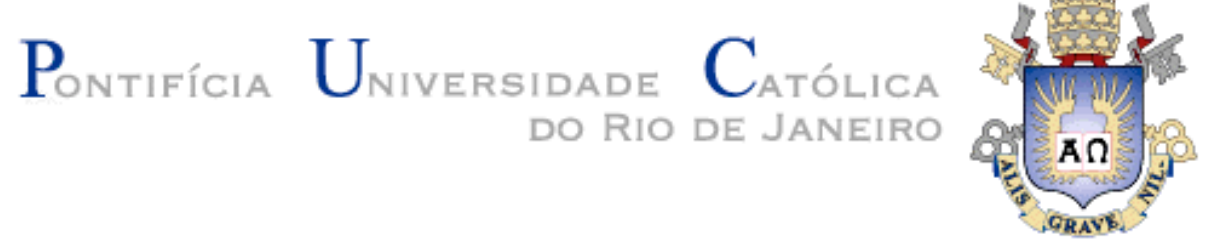

Carla Cristina da Costa Teixeira

\title{
CRIATIVIDADE, DESIGN THINKING E VISUAL THINKING E SUA RELAÇÃO COM O UNIVERSO DA INFOGRAFIA E DA VISUALIZAÇÃO DE DADOS
}

Tese de Doutorado

Tese apresentada ao Programa de Pós-Graduação em Design da PUC-Rio como requisito parcial para obtenção do título de Doutor em Design.

Orientador: Prof. Nilton Gonçalves Gamba Junior

Rio de Janeiro, abril de 2014 


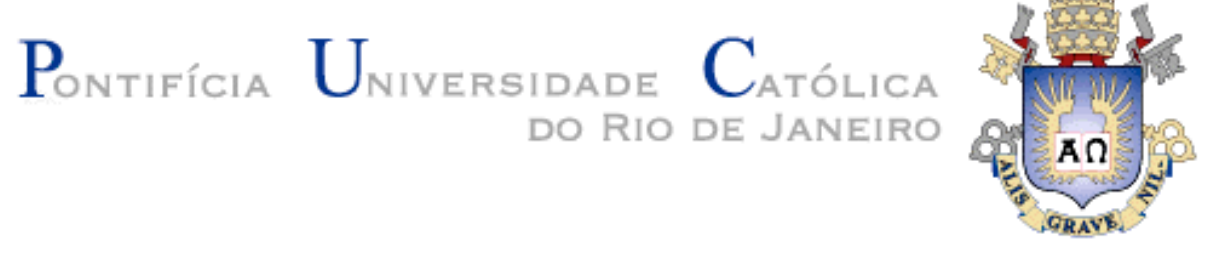

Carla Cristina da Costa Teixeira

Criatividade, Design Thinking e Visual Thinking e sua relação com o universo da infografia e da visualização de dados

Tese apresentada ao Programa de Pós-Graduação em Design da PUC-Rio como requisito parcial para obtenção do grau de Doutor em Design. Aprovada pela Comissão Examinadora abaixo assinada.

Prof. Nilton Gonçalves Gamba Junior

Orientador

Departamento de Artes \& Design - PUC-Rio

Prof. Marcelo Fernandes Pereira

Departamento de Artes \& Design - PUC-Rio

Prof. Ricardo Artur Pereira Carvalho

Departamento de Artes \& Design - PUC-Rio

Prof. Fabio Mario Iorio

Universidade Estadual do Rio de Janeiro - UERJ

Profa. Ana Beatriz Pereira de Andrade

Universidade Estadual Paulista - UNESP

Profa. Denise Berruezo Portinari Coordenadora Setorial do Centro de Teologia

e Ciências Humanas - PUC-Rio

Rio de Janeiro, 14 de abril de 2014 
Todos os direitos reservados. É proibida a reprodução total ou parcial do trabalho sem autorização da universidade, da autora e do orientador.

\section{Carla Cristina da Costa Teixeira}

Mestre em Design pela PUC-Rio desde 2006. Graduou-se em Comunicação Social, com habilitação em Jornalismo, na UERJ, em 2001. MBA em Gestão de Negócios pela UVARJ. É professora adjunta da Universidade Veiga de Almeida, nas Faculdades de Design, Engenharia e Comunicação Social desde 2006. É professora colaborada na PUC-Rio. Já atuou como docente na Faculdade de Comunicação da UERJ e Graduação e Pós-Graduação no SENAC-Rio. Pesquisadora e consultora nas áreas de inovação e criatividade, design thinking, visual thinking, design da informação, infografia, visualização de dados, cultura pós-moderna, cibercultura, novas tecnologias e mídias digitais.

Ficha Catalográfica

Teixeira, Carla Cristina da Costa

Criatividade, Design Thinking e Visual Thinking e sua relação com $o$ universo da infografia $e$ da visualização de dados / Carla Cristina da Costa Teixeira ; orientador: Nilton Gonçalves Gamba Junior. 2014.

196 : il. (color.) ; $30 \mathrm{~cm}$

Tese (doutorado)-Pontifícia Universidade Católica do Rio de Janeiro, Departamento de Artes e Design, 2014

Inclui bibliografia

1. Artes e design - Teses. 2. Infografia. 3. Infográfico. 4. Visualização de dados. 5. Inovação. 6 . Criatividade. 7. Design thinking. 8. Visual thinking. 9. Pensamento visual. I. Gamba Junior, Nilton Gonçalves. II. Pontifícia Universidade Católica do Rio de Janeiro. Departamento de Artes e Design. III. Título. 
Para meu querido avô Augusto.

Na sua simplicidade, foi sempre o maior incentivador da minha educação.

Minha eterna gratidão. 


\section{Agradecimentos}

Ao meu caro orientador, Prof. Dr. Nilton Gamba Jr., por todo o auxílio e orientação prestados durante a tese. Agradeço também a confiança, mesmo diante de momentos críticos e mudanças de abordagem. Muito obrigada.

Aos ilustres e queridos professores que, gentilmente, aceitaram participar da Comissão Examinadora: Prof. Dr. Ana Beatriz Andrade, Prof. Dr. Fabio Iorio, Prof. Dr. Marcelo Pereira e Prof. Dr. Ricardo Artur Carvalho. E também à querida suplente Prof. Dr. Cassia Figueiredo. Tenho o orgulho e honra de poder chamá-los de amigos.

Aos caros Prof. Dr. Claudio Magalhães e Prof. Dr. Luis Bittencourt por terem participado da banca de qualificação, fornecendo dicas valiosas e fundamentais para o bom prosseguimento da tese. Muito obrigada pela contribuição.

Ao gentilíssimo Prof. Alberto Cairo, sempre disposto em me auxiliar de diferentes formas desde o início da tese. Sua imensa generosidade e seu grande conhecimento nas áreas de infografia e visualização nunca serão esquecidos por mim. Minha eterna gratidão.

Aos professores Eliane Garcia e Gilberto Mendes por terem permitido a aplicação do estudo de caso na disciplina ministrada por eles na PUC-Rio, e aos seus alunos de Desenho Industrial que participaram de muito bom grado do workshop. Com certeza, foi um auxílio prestado inestimável. Obrigada pela confiança e amizade.

Aos meus caríssimos amigos, aos meus pais pelo apoio irrestrito e por sempre 
acreditarem em mim, ao meu querido Daniel, e à toda a minha família, inclusive a de coração, que tiveram paciência e compreensão suficientes para entender meu crescente estresse e ausência em datas especiais, além de escutar minhas aflições nos momentos mais difíceis da tese.

Aos meus amigos da PUC-Rio, pelo apoio e momentos de descontração por compartilharmos da mesma jornada.

Aos funcionários da PUC-Rio por toda ajuda e esclarecimentos fornecidos durante o desenvolvimento da tese.

A Deus e ao Universo, por terem me dado o amor infinito e o apoio necessário para que pudesse vencer mais essa etapa da minha vida. 


\section{Resumo}

Teixeira, Carla Cristina da Costa; Gamba Junior, Nilton Gonçalves. Criatividade, Design Thinking e Visual Thinking e sua relação com o universo da infografia e da visualização de dados. Rio de Janeiro, 2014. 196p. Tese de Doutorado - Departamento de Artes \& Design, Pontifícia Universidade Católica do Rio de Janeiro.

A tese discute a relação existente entre a criatividade e o design thinking e o universo da infografia e da visualização de dados, com destaque para a criação de um método de construção de infográficos a partir dos estudos empreendidos nas referidas áreas, baseados em bibliografia compatível e atual. Através principalmente da lógica do visual thinking, é elaborado um método de construção de infográficos. Além disso, o próprio infográfico aparece como possível ferramenta de pensamento visual dentro do design thinking, otimizando as possibilidades desse processo. A infografia e a visualização de dados disponibilizam um novo e vasto campo de trabalho para o designer em parceria com outros profissionais. No entanto, existe uma carência de métodos de construção e desenvolvimento de infográficos. O método de construção proposto pela tese para preencher essa lacuna identificada, até pela minha própria prática profissional de ensino, poderá ser aplicado tanto por designers já atuantes no mercado quanto ensinado a estudantes de Design ou Comunicação.

\section{Palavras-chave}

Infografia; infográfico; visualização de dados; inovação; criatividade; design thinking; visual thinking; pensamento visual. 


\begin{abstract}
Teixeira, Carla Cristina da Costa; Gamba Junior, Nilton Gonçalves (Advisor). Creativity, design thinking and visual thinking and its relation with the universe of infographics and data visualization. Rio de Janeiro, 2014. 196p. Doctoral Thesis - Departamento de Artes \& Design, Pontifícia Universidade Católica do Rio de Janeiro.
\end{abstract}

The thesis discusses the relationship between creativity and design thinking and the universe of infographics and data visualization, proposing a method of construction of infographics from studies in these areas, based on current and compatible bibliography. The method of development of infographics follows the logic that belongs to visual thinking. In addition, the infographics itself appears as a possible tool for visual thinking within the design thinking, optimizing the possibilities of this process. Infographics and data visualization provide a vast new field of work for the designer in partnership with other professionals. However, there is a lack of methods for building and developing infographics. The method of construction proposed by the thesis to fill this gap identified, including my own experience as a professor in this area, can be applied both by designers who are already in the market as can be taught to students of Design and Communication.

\title{
Keywords
}

Infographics; infographic; data visualization; innovation; creativity; design thinking; visual thinking; visual thinking. 


\section{Sumário}

1. Introdução

2. Infografia, infovis e visualização de dados: conceitos e definições

2.1 Dado, informação e conhecimento

2.2 Infografia

2.3 Visualização de informação ou infovis

2.4 Visualização de dados

3. A criatividade e e sua relação com a infografia e a visualização de dados

3.1 que é criatividade?

3.2 Modos cerebrais CREATES

$\begin{array}{ll}\text { 3.3 Modelo das quatro dimensões da criatividade } & 68\end{array}$

3.4 Tipos de pensamento: divergente, convergente, lateral e vertical 72

3.5 Bloqueios criativos da percepção e modelos mentais 75

$\begin{array}{ll}\text { 3.6 Modelos Mentais } & 78\end{array}$

4. Design thinking, infografia e visualização de dados: criatividade e inovação

4.1 O que é design thinking e sua relação com a inovação 84

4.2 Mistério, heurística e algoritmo: o funil do conhecimento

4.3 Pensamento abdutivo: o equilíbrio entre o analítico e o intuitivo 
5 - Elaboração de infográficos a partir do visual thinking

e de conceitos relacionados

$5.11^{\text {a }}$ etapa: olhar ou coletar dados

$5.22^{\mathrm{a}}$ etapa: ver ou selecionar e criar padrões com dados

$5.33^{\mathrm{a}}$ etapa: imaginar ou estabelecer conexões não aparentes, com o uso do SQVID

$5.44^{\mathrm{a}}$ etapa: mostrar ou tradução visual das etapas anteriores, com as escolha de recursos gráficos

5.5 Estudo de caso: aplicação das ferramentas de visual thinking de Dan Roam na construção de infográficos

5.6 Matriz de construção de infográficos baseado no visual thinking e no design thinking

6. Considerações finais

7. Referências bibliográficas 
Aquele que age conscientemente e se esforça pacientemente, obtém riquezas. Com a retidão de caráter, alcança a fama. Praticando o bem, cria laços de amizade.

Siddhartha Gautama 